\title{
Neurotropism as a prognostic factor in cutaneous melanoma patients
}

\author{
F. TAS*, K. ERTURK \\ Institute of Oncology, University of Istanbul, Istanbul, Turkey \\ *Correspondence: faruktas2002@yahoo.com
}

Received April 26, 2017 / Accepted July 12, 2017

\begin{abstract}
Neurotropism is a feature that is encountered rarely in melanoma and is considered to be associated with increased risk of local recurrence. However, its prognostic significance still remains controversial. The objective of this study was to determine the clinical significance of neurotropism in cutaneous melanoma patients. A total of 519 cutaneous melanoma patients were enrolled into this study and their data were analyzed in a retrospective fashion. The melanomas without neurotropism $(n=496 ; 95.6 \%)$ were larger in number than those with neurotropism $(n=23 ; 4.4 \%)$. Compared to non-neurotropic melanomas, neurotropic melanomas were more likely localized in the extremities $(\mathrm{p}=0.007)$ and they were more frequently associated with non-superficial spreading histologic subtype ( $\mathrm{p}=0.029)$, advanced Clark invasion level (IV-V) $(\mathrm{p}=0.007)$, thick Breslow depth $(\mathrm{p}=0.001)$, high mitotic rate $(\mathrm{p}=0.041)$, ulcerated lesions $(\mathrm{p}<0.001)$, lymphovascular invasion $(\mathrm{p}<0.001)$, and lymph node metastasis $(\mathrm{p}=0.013)$. The neurotropic melanomas were significantly associated with both unfavorable relapse-free survival (RFS) ( $\mathrm{p}=0.045)$ and overall survival (OS) $(\mathrm{p}<0.001)$. However, neurotropism lost its prognostic significance in both RFS $(p=0.767)$ and OS $(p=0.644)$ in multivariable analyses. In conclusion, the presence of neurotropism predicts a greater risk for nodal involvement and is associated with worse survival in patients with cutaneous malignant melanoma, on the other hand it is not an independent risk factor when other powerful prognostic variables are considered.
\end{abstract}

Key words: neurotropism, melanoma, prognostic, survival

Neurotropism is defined as neoplastic infiltration of nerve fibers with extension of the tumor along the surrounding nerves and displayes prominent Schwannian differentiation and/or extensive perineural invasion (PNI) [1]. A comprehensive understanding of the biological processes that promote PNI has yet to be established in malignancy with a propensity for neurotropism. The potential explanations in the pathogenesis of neurotropism have been proposed; tumor cells adopt a phenotype that enables them to respond to the distinctive microenvironment of nerves and thus acquire properties of enhanced invasiveness and proliferation. In the other, tumors may develop a microenvironment that promotes neural expansion, resulting in the proliferation of nerve branch into and around the tumor with resulting neurotropism [1]. It is likely that these mechanisms both occur at some level at the same time through reciprocal signaling between nerve and tumor cells. The correlation of neurotropism with poor outcomes in several cutaneous and noncutaneous malignancies suggests that considering neurotropism as a histopathologic variable would help clarify its precise prognostic relevance [1].
In melanoma, neurotropism is defined by spread and direct invasion of melanoma cells along the neural structures, i.e. perineurium or, occasionally, endoneurium [1-7]. Although neurotropism is a common feature in desmoplastic melanoma, which is classified as desmoplastic neurotropic melanoma (DNM), it may also be encountered in other forms of melanoma, albeit rather rarely. Neurotropic melanomas which show strictly perineural and/or endoneural involvement without desmoplasia have been very rarely reported, i.e. they comprise only less than $1 \%$ of all melanomas $[1,2]$. Because of its rarity, neurotropism is frequently investigated in the studies as a feature integrated with DNM. Since it tends to invade deeply at the primary site and has a high potential to have positive pathological margin after surgical excision the presence of neurotropism is believed to be associated with an increased risk of local recurrence and worse prognosis in melanoma $[1,3-5]$.

Since neurotropism has been investigated in only a few numbers of studies regarding its prognostic value in melanoma, its clinical significance still remains largely unknown [1, 3-7]. In this study, we evaluated the neurotro- 
pism status in cutaneous melanoma patients, and assessed its associations with the prognosis and miscellaneous clinical variables with the intention of figuring out whether the presence of neurotropism in melanoma might be a potential prognostic indicator, or not.

\section{Materials and methods}

The data of 1167 histologically confirmed adult cutaneous melanoma patients admitted to and treated in Institute of Oncology, Istanbul University, between the years of 1993 and 2015 were analyzed retrospectively. A total of 519 patients with known neurotropism status were included in the cohort. The disease was staged according to the American Joint Committee on Cancer (AJCC) staging system. Lymph node involvement was determined by either sentinel lymph node (SLN) biopsy or lymph node dissection. Patients with pathologically positive SLN underwent a completion lymphadenectomy. Patients were treated and followed-up according to standard guidelines.

The presence of neurotropism was accepted positive when perineural or intraneural invasion by neoplastic cells was detected (Figure 1). Regression was defined as a replacement of tumor cells by lymphocytic inflammation as well as attenuation of the epidermis and non-laminated dermal fibrosis with inflammatory cells, melanophagocytosis, and telangiectasia. In complete, as opposed to partial regression, there is a total absence of neoplastic melanocytes in the dermis and in the overlying epidermis. Evaluations of lymphovascular invasion (LVI) were performed by using at least a minimum of $\times 100$ magnification. Slides were stained by H\&E. For equivocal cases, CD31 and D2-40 antibodies were applied for IHC assessment. LVI was confirmed by the presence of tumor cell groups in the lumen of dermal and subcutaneous lymphatic or blood vessels located adjacent to or around the lesion. A two-tier tumor infiltrating lymphocytes (TILs) density grading schema (absent and present) was used to assess TILs density: no TILs infiltration was designated as (i) TILs absent; and any type of infiltration (mild, moderate and marked) were defined as (ii) TILs present. The remaining other tumor related pathological factors, such as histopathology, Clark invasion level, Breslow thickness, mitotic rate, ulceration, vertical growth phase and association with a pre-existing melanocytic nevus were determined by the institution's dermatopathologists using standard pathological definitions and procedures.

For comparisons, we also determined the standard cut-off points of each pathological variables, such as early (level I-III) versus advanced (level IV-V) for Clark level, thin $(<2 \mathrm{~mm})$ versus thick $(\geq 2 \mathrm{~mm})$ for Breslow depth, low $\left(\leq 3 / \mathrm{mm}^{2}\right)$ versus high $\left(>3 / \mathrm{mm}^{2}\right)$ mitotic rate, and presence versus absence for other pathological parameters such as ulceration, tumor-infiltrating lymphocyte, lymphovascular invasion, neurotropism, vertical growth phase, and association with a pre-existing melanocytic nevus.
The study was reviewed and approved by our local ethical committee. Comparisons between various clinicopathological variables and neurotropism status were done using $\chi^{2}$ (chi-square) tests. Relapse-free survival (RFS) was calculated from the date of pathologic diagnosis to the date of the clinical recurrence which was defined as detected by imaging studies or by clinical examination. Overall survival (OS) was calculated from the date of pathologic diagnosis to death resulting from any cause. Kaplan-Meier analysis was used for estimation of survival of patient and differences in survivals were assessed by the log-rank statistics. Univariate and multivariable analyses were performed using Cox proportional hazards models. A p-value $\leq 0.05$ was considered significant. Statistical analysis was carried out using SPSS 21.0 software (SPSS Inc., Chicago, Illinois, USA).

\section{Results}

The data of 519 melanoma patients were analyzed in the study. The median age of patients was 53 years, ranging from 16 to 104 years. Other demographical and clinicopathological characteristics are shown in Table 1 . The number of melanomas without neurotropism $(n=496 ; 95.6 \%)$ were greater than that with neurotropism $(n=23 ; 4.4 \%)$. Compared to non-neurotropic melanomas, neurotropic melanomas were more likely localized in the extremities (69.6\% vs. $41.3 \%$; $\mathrm{p}=0.007$ ), and they were more frequently associated with non-superficial spreading histologic subtype (68.2\% vs. $44.4 \% ; \mathrm{p}=0.029)$, advanced Clark invasion level $(\mathrm{IV}-\mathrm{V})(95.5 \%$ vs. $68.4 \%$; $=0.007)$, thick Breslow depth $(\geq 2 \mathrm{~mm}) \quad(95.7 \%$ vs. $62.5 \%$; $\mathrm{p}=0.001)$, high mitotic rate $\left(>3 / \mathrm{mm}^{2}\right)(60.0 \%$ vs. $37.3 \% ; \mathrm{p}=0.041)$, ulcerated lesions (90.5\% vs. $49.9 \%$; $\mathrm{p}<0,001)$, lymphovascular invasion $(38.1 \%$ vs. $9.4 \% ; \mathrm{p}<0.001)$, and lymph node metastasis $(68.4 \%$ vs. $39.6 \% ; \mathrm{p}=0.013$ ) (Table 1). On the other hand, neurotropism was not associated with age, sex, TIL, vertical growth

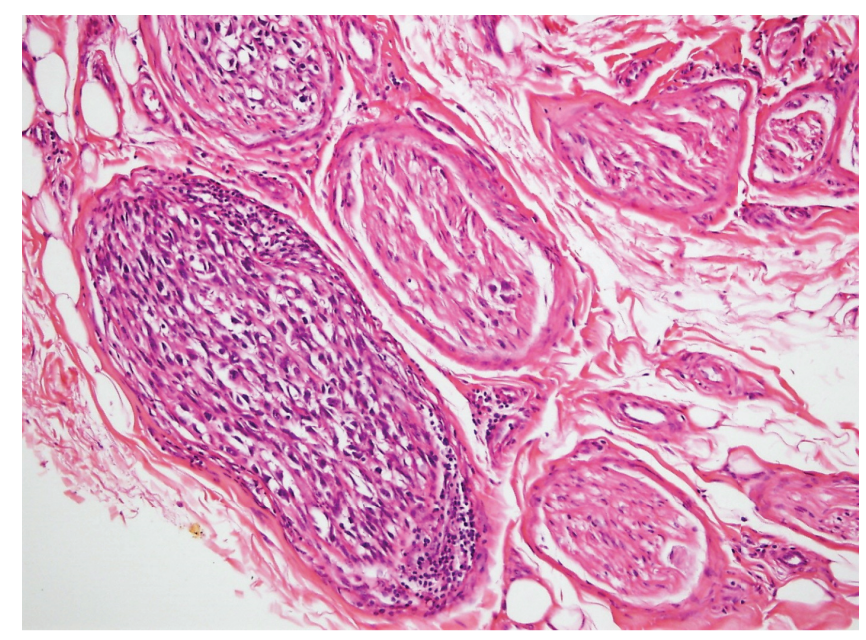

Figure 1. Intraneural invasion by neoplastic cells (neurotropism) in a case of malignant melanoma (Hematoxylin eosin $\times 20$, original magnification). 
Table 1. Patient characteristics and correlations between neurotropism and various clinicopathological variables.

\begin{tabular}{|c|c|c|c|c|}
\hline \multirow[b]{2}{*}{ Variables } & \multicolumn{4}{|c|}{ Neurotropism } \\
\hline & n (\%) & $(-)$ & $(+)$ & p-value \\
\hline No. of patients & $519(100.0)$ & 496 (95.6) & $23(4.4)$ & \\
\hline \multicolumn{5}{|l|}{ Age } \\
\hline$<50$ years & $217(41.8)$ & $208(41.9)$ & $9(39.1)$ & \multirow{2}{*}{0.79} \\
\hline$\geq 50$ years & $302(58.2)$ & $288(58.1)$ & $14(60.9)$ & \\
\hline \multicolumn{5}{|l|}{ Sex } \\
\hline Male & $271(52.2)$ & $257(51.8)$ & $14(60.9)$ & \multirow{2}{*}{0.395} \\
\hline Female & $248(47.8)$ & 239 (48.2) & $9(39.1)$ & \\
\hline \multicolumn{5}{|l|}{ Site of lesion } \\
\hline Axial & $298(57.4)$ & $291(58.7)$ & $7(30.4)$ & \multirow{2}{*}{0.007} \\
\hline Extremity & $221(42.6)$ & $205(41.3)$ & $16(69.6)$ & \\
\hline \multicolumn{5}{|l|}{ Histology } \\
\hline $\begin{array}{l}\text { Superficial } \\
\text { Spreading }\end{array}$ & $267(54.5)$ & $260(55.6)$ & $7(31.8)$ & \multirow{2}{*}{0.029} \\
\hline Others & $223(45.5)$ & $208(44.4)$ & $15(68.2)$ & \\
\hline \multicolumn{5}{|l|}{ Histology } \\
\hline Nodular & $116(23.7)$ & $110(23.5)$ & $6(27.3)$ & \multirow{2}{*}{0.684} \\
\hline Others & $374(76.3)$ & $358(76.5)$ & $16(72.7)$ & \\
\hline \multicolumn{5}{|l|}{ Clark level } \\
\hline I-III & $156(30.4)$ & $155(31.6)$ & $1(4.5)$ & \multirow{2}{*}{0.007} \\
\hline IV-V & 357 (69.6) & $336(68.4)$ & $21(95.5)$ & \\
\hline \multicolumn{5}{|c|}{ Breslow thickness } \\
\hline$<2 \mathrm{~mm}$ & $185(36.0)$ & $184(37.5)$ & $1(4.3)$ & \multirow{2}{*}{0.001} \\
\hline$\geq 2 \mathrm{~mm}$ & $329(64.0)$ & $307(62.5)$ & $22(95.7)$ & \\
\hline \multicolumn{5}{|c|}{ Tumor infiltrating lymphocytes } \\
\hline Present & $301(59.6)$ & $288(59.5)$ & $13(61.9)$ & \\
\hline Absent & $204(40.4)$ & $196(40.5)$ & $8(38.1)$ & 0.826 \\
\hline Mitotic rate & & & & \\
\hline$\leq 3 / \mathrm{mm}^{2}$ & $310(61.8)$ & $302(62.7)$ & $8(40.0)$ & \\
\hline$>3 / \mathrm{mm}^{2}$ & $192(38.2)$ & $180(37.3)$ & $12(60.0)$ & 0.041 \\
\hline Ulceration & & & & \\
\hline Present & $262(51.6)$ & 243 (49.9) & $19(90.5)$ & \\
\hline Absent & $246(48.4)$ & $244(50.1)$ & $2(9.5)$ & $<0.001$ \\
\hline Vertical growth & & & & \\
\hline Present & $256(89,5)$ & $243(89.0)$ & $13(100.0)$ & \\
\hline Absent & $30(10.5)$ & $30(11.0)$ & $0(0.0)$ & 0.206 \\
\hline Lymphovascula & ion & & & \\
\hline Present & $53(10.6)$ & $45(9.4)$ & $8(38.1)$ & \\
\hline Absent & $448(89.4)$ & $435(90.6)$ & $13(61.9)$ & $<0.001$ \\
\hline Regression & & & & \\
\hline Present & $109(23.0)$ & $106(23.5)$ & $3(14.3)$ & \\
\hline Absent & $364(77.0)$ & $346(76.5)$ & $18(85.7)$ & 0.33 \\
\hline Association wit & existing mela & ocytic nevus & & \\
\hline Present & $117(28.8)$ & $113(28.9)$ & $4(26.7)$ & \\
\hline Absent & $289(71.2)$ & $278(71.1)$ & $11(73.3)$ & 0.851 \\
\hline Lymph node in & lent & & & \\
\hline Yes & $156(41.1)$ & $143(39.6)$ & $13(68.4)$ & \\
\hline No & $224(58.9)$ & $218(60.4)$ & $6(31.6)$ & 0.013 \\
\hline No. of involved & nodes & & & \\
\hline 1 & $79(51.0)$ & $72(50.7)$ & $7(53.8)$ & \\
\hline$\geq 2$ & $76(49.0)$ & $70(49.3)$ & $6(46.2)$ & 0.828 \\
\hline Metastasis & & & & \\
\hline Present & $23(4.4)$ & $21(4.2)$ & $2(8.7)$ & \\
\hline Absent & $496(95.6)$ & 475 (95.8) & $21(91.3)$ & 0.309 \\
\hline Type of metast & & & & \\
\hline M1a-b & $7(30.4)$ & $7(33.3)$ & $0(0.0)$ & \\
\hline M1c & $16(69.6)$ & $14(66.7)$ & $2(100.0)$ & 0.474 \\
\hline Recurrence & & & & \\
\hline Yes & $124(23.9)$ & $116(23.4)$ & $8(34.8)$ & \\
\hline No & $395(76.1)$ & $380(76.6)$ & $15(65.2)$ & \\
\hline
\end{tabular}

phase, regression, underlying precursor lesion and multiple lymph node involvement. Similarly, no correlation was found between neurotropism and other parameters such as presence of recurrence $(\mathrm{p}=0.210)$, metastasis $(\mathrm{p}=0.309)$, and certain type of metastasis $(\mathrm{p}=0.474)$.

In univariate analysis of possible clinicopathological variables, male sex, nodular histology, advanced Clark invasion level, thick Breslow depth, high mitotic rate, ulcerated lesions, lymphovascular invasion, and lymph node involvement were identified as unfavorable prognostic factors for both RFS and OS. Furthermore, presence of recurrence and distant metastasis were also correlated with unfavorable OS. On the other hand, variables such as age, tumor localization, TIL, regression, and underlying precursor lesion were not associated with either survival. However, we found that presence of neurotropism was associated with poor RFS $(\mathrm{p}=0.045)$ and $\mathrm{OS}(\mathrm{p}<0.001$, Table 2, Figure 2$)$.

In multivariable analyses, high mitotic rate [HR $(95 \% \mathrm{CI})$ : $1.683(1.074-2.637, \mathrm{p}=0.023$ ], ulcerated lesions [HR (95\%CI): $1.872(1.151-3.046), \mathrm{p}=0.012]$, and lymph node involvement [HR (95\%CI): 3.281 (2.064-5.216), p<0.001] remained significant for poor RFS, whereas lesions with nodular histology [HR (95\%CI): 0.550 (0.330-0.917), p=0.022], lymphovascular invasion [HR (95\%CI): 2.113 (1.168-3.820), $\mathrm{p}=0.013$ ], recurrence [HR (95\%CI): $11.21(6.295-19.97), \mathrm{p}<0.001]$, and metastatic disease [HR (95\%CI): 18.61 (7.963-43.50), $\mathrm{p}<0.001]$ remained significant for poor OS. However, the prognostic significance of neurotropism was confounded for both RFS ( $\mathrm{p}=0.767)$ and OS $(\mathrm{p}=0.644)$.

\section{Discussion}

In this study, we investigated the prognostic significance of histological neurotropism in primary cutaneous melanoma patients. Our findings revealed that presence of neurotropism might be used as a predictor of nodal involvement in melanoma and it was associated with poor survival even though it was not identified as an independent risk factor when adjusted for other powerful prognostic variables.

So far a very few number of studies have analyzed the prognostic role of neurotropism in cutaneous melanoma and they have brought out conflicting results [1,3-7]. A study on 421 stage I cutaneous melanoma patients showed that neurotropism was associated with poor prognosis on survival [3]. Similarly, local recurrence rate of the cutaneous melanomas with neurotropism was found significantly increased $(20 \%$ vs. 3\%). However, another study concluded that even though neurotropism was correlated with a 2 -fold increase in local recurrence it was not associated with survival [4]. Since then, majority of studies reported that presence of neurotropism in melanoma was not of prognostic significance [5-7]. In a recent trial, neurotropism was shown to be associated with local recurrence whereas it had no impact on disease-free or overall survival in multivariate analyses [5]. Considering our study, we concur with these results. 

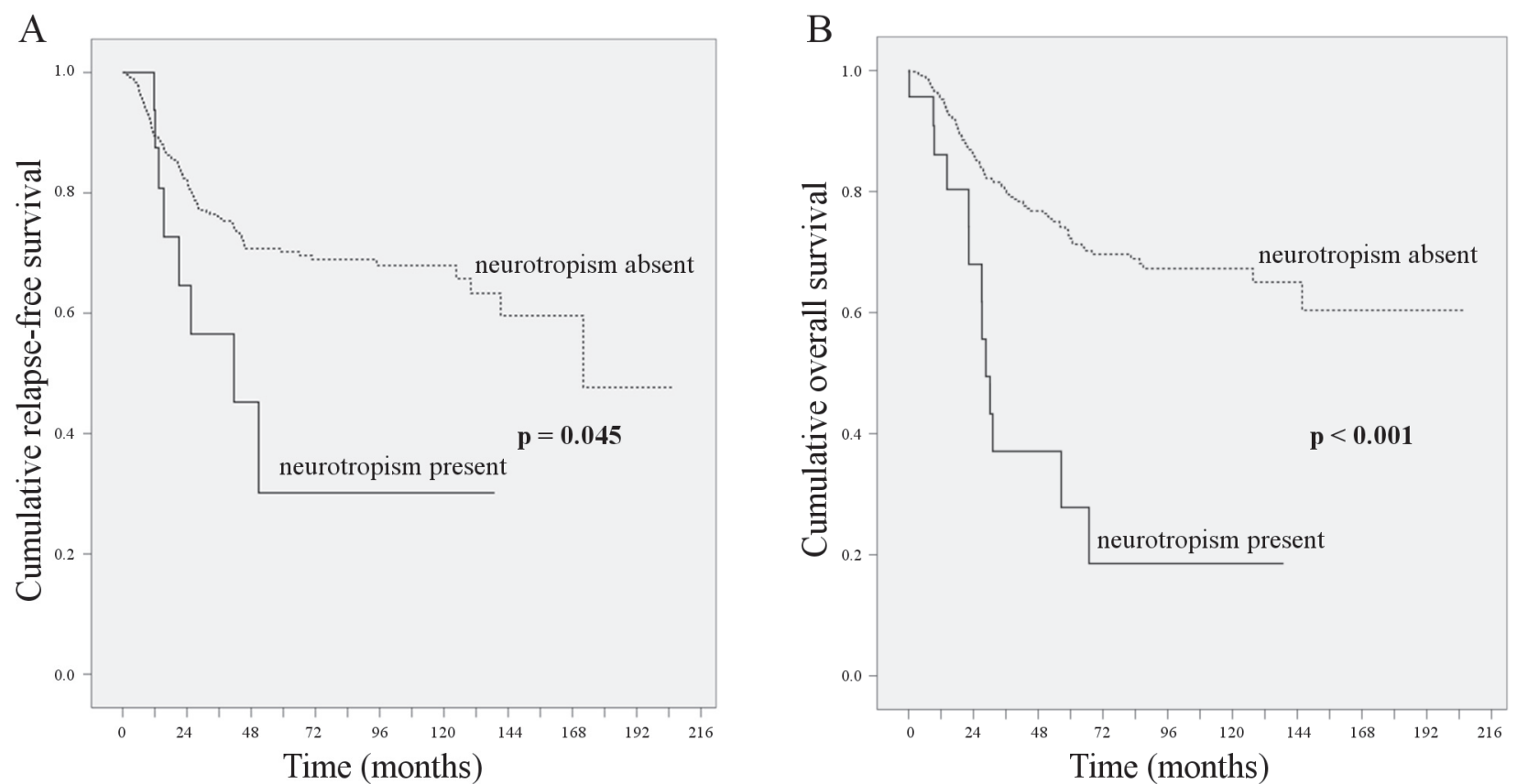

Figure 2. A) Relapse-free survival curves in melanoma patients according to the neurotropism status, B) overall survival curves in melanoma patients according to the neurotropism status.

Table 2. Univariate analyses of variables associated with relapse-free survival (RFS) and overall survival (OS).

\begin{tabular}{|c|c|c|c|c|}
\hline & \multicolumn{2}{|c|}{ Relapse-free survival (RFS) } & \multicolumn{2}{|c|}{ Overall survival (OS) } \\
\hline & HR $(95 \% \mathrm{CI})$ & p-value & $\mathrm{HR}(95 \% \mathrm{CI})$ & p-value \\
\hline Age ( $<50$ vs. $\geq 50$ years $)$ & $0.933(0.654-1.332)$ & 0.704 & $1.098(0.762-1.582)$ & 0.616 \\
\hline Sex (male vs. female) & $0.576(0.399-0.831)$ & 0.003 & $0.619(0.428-0.894)$ & 0.011 \\
\hline Site of lesion (axial vs. extremity) & $0.950(0.664-1.360)$ & 0.781 & $0.948(0.659-1.362)$ & 0.772 \\
\hline Histology (superficial spreading vs. others) & $1.404(0.969-2.034)$ & 0.073 & $1.530(1.048-2.234)$ & 0.028 \\
\hline Histology (nodular vs. others) & $0.544(0.366-0.806)$ & 0.002 & $0.446(0.301-0.659)$ & $<0.001$ \\
\hline Clark level (I-III vs. IV-V) & $3.308(1.978-5.533)$ & $<0.001$ & $3.596(2.091-6.184)$ & $<0.001$ \\
\hline Breslow thickness ( $<2$ vs. $\geq 2 \mathrm{~mm})$ & $3.308(1.978-5.533)$ & $<0.001$ & $3.497(2.162-5.658)$ & $<0.001$ \\
\hline Tumor infiltrating lymphocytes (present vs. absent) & $0.732(0.508-1.053)$ & 0.092 & $0.702(0.485-1.016)$ & 0.061 \\
\hline Mitotic rate $\left(\leq 3\right.$ vs. $\left.>3 / \mathrm{mm}^{2}\right)$ & $2.446(1.691-3.539)$ & $<0.001$ & $2.399(1.655-3.477)$ & $<0.001$ \\
\hline Ulceration (present vs. absent) & $3.019(2.046-4.454)$ & $<0.001$ & $3.666(2.416-5.564)$ & $<0.001$ \\
\hline Vertical growth phase (present vs. absent) & $8.881(1.222-64.58)$ & 0.031 & $24.15(0.524-1113)$ & 0.103 \\
\hline Lymphovascular invasion (present vs. absent) & $2.010(1.200-3.366)$ & 0.008 & $2.766(1.718-4.453)$ & $<0.001$ \\
\hline Regression (present vs. absent) & $0.737(0.457-1.189)$ & 0.211 & $0.733(0.450-1.195)$ & 0.213 \\
\hline $\begin{array}{l}\text { Association with a preexisting melanocytic nevus } \\
\text { (present vs. absent) }\end{array}$ & $0.851(0.539-1.345)$ & 0.49 & $0.866(0.537-1.398)$ & 0.557 \\
\hline Lymph node involvement (yes vs. no) & $4.071(2.715-6.104)$ & $<0.001$ & $4.007(2.593-6.190)$ & $<0.001$ \\
\hline No. of involved lymph nodes ( 1 vs. $\geq 2$ ) & $1.424(0.877-2.312)$ & 0.153 & $1.446(0.867-2.441)$ & 0.157 \\
\hline Metastasis (present vs. absent) & - & - & $18.33(1.96-30.65)$ & $<0.001$ \\
\hline Type of metastasis (M1a-b vs. M1c) & - & - & $2.785(0.889-8.725)$ & 0.079 \\
\hline Recurrence (yes vs. no) & - & - & $8.442(5.683-12.54)$ & $<0.001$ \\
\hline Neurotropism (present vs. absent) & $2.083(1.015-4.274)$ & 0.045 & $3.706(2.079-6.607)$ & $<0.001$ \\
\hline
\end{tabular}

Although neurotropic melanomas rarely metastasize to distant sites, their local recurrence rates are quite high [3-5] and they tend to spread to regional lymph nodes (8). In a meta-analysis on five studies neurotropism was found to be significantly associated with high likelihood of nodal metastases, so were prognostic factors such as ulceration and satellosis [8]. As these studies concluded, we too suggested that presence of neurotropism might be used as a predictor for lymphatic metastasis. We also found significant correlations between neurotropism and other powerful predictors 
for nodal involvement, such as lesion location and histology, Breslow thickness, Clark level, ulceration, mitotic rate and lymphovascular invasion $[1,8]$.

The controversy between results of studies might have emerged from many factors, two of which are lack of a standard diagnostic definition and poor interobserver reproducibility [2-7]. For example, in the study there was a much weaker agreement in reporting the presence of neurotropism (50\% of cases) compared to absence of neurotropism (96\% of cases) [9]. Additionally, all of the studies were carried out with relatively small sample sizes, a factor which was naturally expected to affect the final analysis. A standardized method is still required to be identified and validated in larger prospective studies.

In conclusion, we found that the presence of neurotropism in melanoma predicts regional lymph node metastasis and it is associated with poor prognosis on survival even though it is not an independent risk factor when adjusted for other known prognostic variables. Therefore, we suggest that besides standard predictors, such as lesion thickness, mitotic rate and ulceration, presence of neurotropism might be as well considered a predicting factor for nodal involvement in melanoma.

\section{References}

[1] FRYDENLUND N, MAHALINGAM M. Desmoplastic melanoma, neurotropism, and neurotrophin receptors - what we know and what we do not. Adv Anat Pathol 2015; 22: 227241. doi: 10.1097/PAP.0000000000000076
[2] NEWLIN HE, MORRIS CG, AMDUR RJ, MENDENHALL WM. Neurotropic melanoma of the head and neck with clinical perineural invasion. Am J Clin Oncol 2005; 28: 399-402.

[3] BAER SC, SCHULTZ D, SYNNESTVEDT M, ELDER DE. Desmoplasia and neurotropism. Prognostic variables in patients with stage I melanoma. Cancer 1995; 76: 2242-2247.

[4] QUINN MJ, CROTTY KA, THOMPSON JF, COATES AS, O'BRIEN CJ et al. Desmoplastic and desmoplastic neurotropic melanoma: experience with 280 patients. Cancer 1998; 83: 1128-1135.

[5] SCANLON P, TIAN J, ZHONG J, SILVA I, SHAPIRO R et al. Enhanced immunohistochemical detection of neural infiltration in primary melanoma: is there a clinical value? Hum Pathol 2014; 45: 1656-1663. doi: 10.1016/j.humpath.2014.04.003

[6] SU LD, FULLEN DR, LOWE L, WANG TS, SCHWARTZ JL et al. Desmoplastic and neurotropic melanoma. Cancer 2004; 100:598-604. doi: 10.1002/cncr.11947

[7] CHEN JY, HRUBY G, SCOLYER RA, MURALI R, HONG A et al. Desmoplastic neurotropic melanoma: a clinicopathologic analysis of 128 cases. Cancer 2008; 113: 2770-2778. doi: 10.1002/cncr.23895

[8] NAGARAJA V, ESLICK GD. Is complete lymph node dissection after a positive sentinel lymph node biopsy for cutaneous melanoma always necessary? A meta-analysis. Eur J Surg Oncol 2013; 39: 669-680. doi: 10.1016/j.ejso.2013.02.022

[9] MONSHIZADEH L, HANIKERI M, BEER TW, HEENAN PJ. A critical review of melanoma pathology reports for patients referred to the Western Australian Melanoma Advisory Service. Pathology 2012; 44: 441-447. doi: 10.1097/ PAT.0b013e328355767e 